\title{
Vascularized Lymph Node Transfer for Lymphedema
}

\author{
Mark V. Schaverien, MBChB, MD, MSc, MEd, FRCS (Plast) ${ }^{1} \quad$ Ido Badash, BS ${ }^{2} \quad$ Ketan M. Patel, MD ${ }^{3}$ \\ Jesse C. Selber, MD, MPH, FACS ${ }^{1}$ Ming-Huei Cheng, MD, MBA ${ }^{4}$
}

1 Department of Plastic Surgery, University of Texas MD Anderson Cancer Center, Houston, Texas

${ }^{2}$ Keck School of Medicine, University of Southern California, Los Angeles, California

${ }^{3}$ Division of Plastic and Reconstructive Surgery, Keck Medical Center of USC, University of Southern California, Los Angeles, California

${ }^{4}$ Department of Plastic Surgery, Chang Gung Memorial Hospital,

Taoyuan, Taiwan

\begin{abstract}
Address for correspondence Ketan M. Patel, MD, Division of Plastic and Reconstructive Surgery, Department of Surgery, Keck Medical Center of USC, University of Southern California, 1510 San Pablo Street, Suite 415, Los Angeles, CA 90033 (e-mail: ketan.patel@med.usc.edu).
\end{abstract}

Semin Plast Surg 2018;32:28-35.

Abstract
Keywords
- lymphedema
- vascularized lymph
node transfer
- flap
- groin
- supraclavicular
- submental
- gastroepiploic
- mesenteric

Advances in our understanding of the lymphatic system and the pathogenesis of lymphedema have resulted in the development of effective surgical treatments. Vascularized lymph node transfer (VLNT) involves the microvascular transplantation of functional lymph nodes into an extremity to restore physiological lymphatic function. It is most commonly performed by transferring combined deep inferior epigastric artery perforator and superficial inguinal lymph node flaps for postmastectomy breast reconstruction. For patients who do not require or are unable to undergo free abdominal breast reconstruction or have lymphedema affecting the lower extremity, several other VLNT options are available. These include flaps harvested from within the axillary, inguinal, or cervical lymph node basins, and lymph node flaps from within the abdominal cavity. This article reviews the lymph node flap options and techniques available for VLNT for lymphedema.
Advances in our understanding of the anatomophysiology of the lymphatic system and the pathogenesis of lymphedema have led to the development of effective surgical techniques to ameliorate the symptoms and disability of patients with lymphedema. Vascularized lymph node transfer (VLNT) involves the transfer of functional lymph nodes, with microanastomosis with vasculature in the recipient bed to maintain their blood supply, to restore physiological lymphatic flow to an extremity in which the native lymph nodes has been removed. $^{1-3}$

The precise mechanism of action is incompletely understood, but two main mechanisms have been demonstrated in the experimental and clinical settings: ${ }^{4-11}$ lymphangiogenesis with new lymphatic collateral pathways connecting with adjacent lymph nodes to restore outflow, mediated by lymphatic growth factor secretion from the transplanted lymph nodes, in particular vascular endothelial growth factor C (VEGF-C); ${ }^{12}$ and neo-lymphangiogenesis establishing new lymphatico-venous drainage within the transplanted lymph nodes, with the "pumping" mechanism driven by perfusion gradients between arterial inflow and venous outflow. These mechanisms support the clinical efficacy of proximal (orthotopic) as well as distal (heterotopic) placement of the VLNs within an extremity. Lymphatico-lymphatic anastomoses are not necessary as new lymphatic connections develop via homing lymphatic growth factor mechanisms, and there is typically a paucity of functioning lymphatic vessels in the recipient extremity in patients that require VLNT.

The advantages of orthotopic VLNT include convenience to combine with free abdominal autologous breast reconstruction, opportunity for radical scar release of the axilla, and concealment of the scar and flap bulk within the axilla. Heterotopic transfer is indicated where lymphedema
Issue Theme Lymphedema Management; Guest Editors: Edward I. Chang, MD, FACS, Mark V. Schaverien, MBChB, MD, MSc, MEd, FRCS (Plast), and Jesse C. Selber, MD, MPH, FACS
Copyright (C 2018 by Thieme Medical Publishers, Inc., 333 Seventh Avenue, New York, NY 10001, USA.

Tel: +1(212) 584-4662.
DOI https://doi.org/ 10.1055/s-0038-1632401. ISSN 1535-2188. 
predominantly affects the distal extremity and hand, and for lymphedema of the lower extremity where there is a gravitational advantage in placing the lymph node transplant distally. ${ }^{6}$

Although VLNT is most commonly performed by transfer of combined deep inferior epigastric artery perforator (DIEP) and superficial inguinal lymph node flaps for postmastectomy breast reconstruction, for patients that have undergone breast-conserving surgery, are unable to undergo free abdominal breast reconstruction, or have lymphedema of the lower extremity, several other VLNT options are available. These include flaps harvested from within the axillary, inguinal, or cervical lymph node basins, including the groin (superficial inguinal lymph nodes), supraclavicular (cervical level Vb lymph nodes), and submental (cervical level Ia/Ib lymph nodes) flaps, as well as from intra-abdominal donor sites including the gastroepiploic and jejunal mesenteric lymph nodes. Although other flaps have been described, clinical experience with their use is limited.

\section{Indications}

Although early lymphedema can be managed effectively by lymphovenous bypass (LVB) surgery alone, in established lymphedema the lymphatic vessels become sclerosed, and LVB surgery may not be possible or fails to provide effective long-term results. ${ }^{13}$ In these patients, VLNT is indicated to provide new physiological function. These patients may also suffer from frequent episodes of cellulitis, which will be substantially reduced by VLNT surgery, possibly by local immunomodulation. ${ }^{14}$ Once significant fibroadipose soft tissue hypertrophy has occurred, physiological treatments may be less effective, and liposuction debulking (or occasionally excisional techniques) may be indicated alone or in staged combination. ${ }^{15-17}$ The presence of significant segmental dermal backflow with few or no functional lymphatic vessels on imaging using indocyanine green (ICG) lymphography, magnetic resonance lymphography, or lymphoscintigraphy suggests that VLNT may be indicated and may help in deciding between orthotopic or heterotopic lymph node transplant placement.

\section{Groin Flap}

The pedicled groin-based flap, described by Clodius et al in 1982 , was the first example of the use of the groin VLN flap to treat lymphedema ${ }^{18}$ (- Fig. 1). Subsequent studies by Chen et al in a canine model and later by Tobbia et al in a sheep model demonstrated the feasibility of the groin VLN flap for the effective drainage of lymphatic fluid for the purposing of reducing limb circumference. ${ }^{5,19}$ Today, the groin is still the most commonly used donor site for VLNT, owing largely to well-described anatomic studies, well-concealed scar, and feasibility to combine it with free abdominal tissue transfer for breast reconstruction. 2,3,20

In the groin region, the anatomic boundaries of the drainage patterns of the lower abdomen and the lower extremity are separated by distinct fascial boundaries. The superficial lymph node basin is known to drain the lower abdomen and is the target of the VLN harvest from this region, whereas deeper lymph node basins that are adjacent to the femoral vessels have been shown to have drainage patterns from the thigh and lower extremity. ${ }^{21,22}$ Anatomic studies have shown the superficial lymph node basin to have an average of three nodes. ${ }^{23,24}$ These nodes are flanked by the superficial circumflex femoral and superficial inferior epigastric vessels and can been found superficially located to the deep fascia of the thigh. This later distinction allows for preservation of the deeper lymphatics draining the lower extremity.

A major advantage of the groin-based flap is the wellhidden donor site scar, which is easily concealed underneath clothes. As a result, this flap may be preferable for patients who value minimal visibility of their scars, as the donor site is the most inconspicuous of all the VLN flap choices. ${ }^{25}$ The wellunderstood vascular anatomy makes the flap easy to use and offers lymphedema surgeons more flexibility while deciding which set of lymph nodes to harvest based on optimal arterial perfusion. The groin VLN flap also has abundant surrounding soft tissue, making it particularly useful in cases where a moderate to large skin paddle is needed.

The major concern with harvesting lymph nodes from the groin is the possibility of causing donor site lymphedema. A

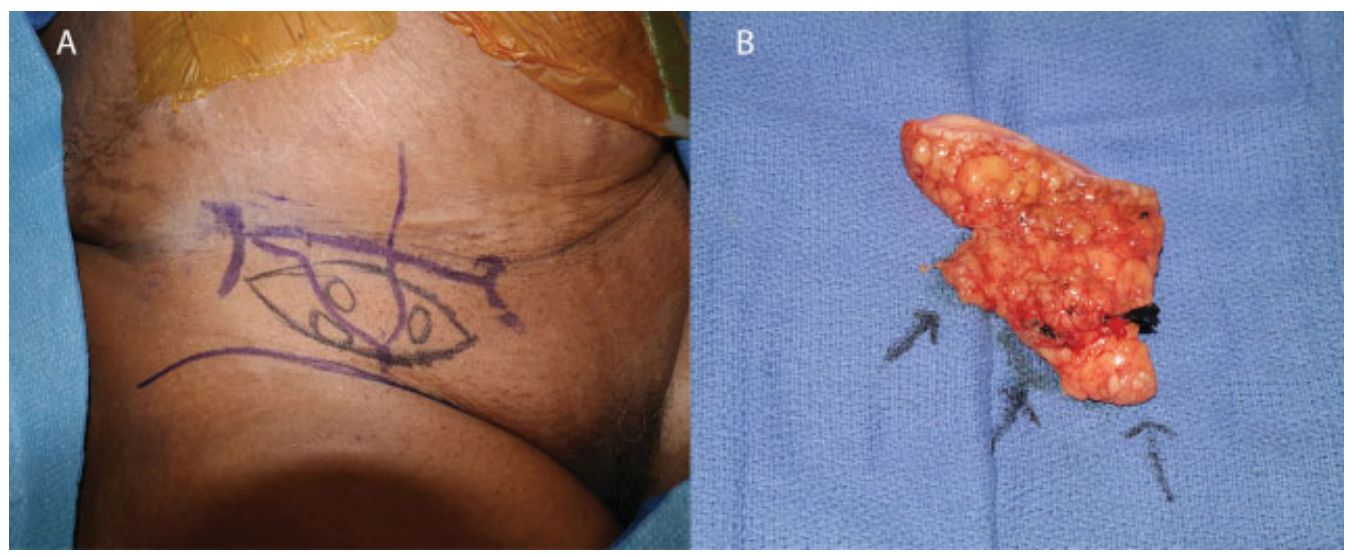

Fig. 1 Groin vascularized lymph node flap. (A) Skin markings for the groin flap; (B) groin flap after harvest with three identified lymph nodes. 
study by Vignes et al found that $38 \%$ of patients undergoing groin VLNT developed complications, the most frequent of which was iatrogenic ipsilateral limb lymphedema. ${ }^{26}$ Therefore, it is critical to avoid harvesting the sentinel nodes draining the lower extremity from the groin and also to avoid harvest of the deep inguinal nodes, which may cause lower extremity lymphedema if removed. ${ }^{21}$ The use of preoperative lymphoscintigraphy and intraoperative gamma probe to detect sites of radionuclide tracer accumulation can help minimize the risk of iatrogenic lymphedema from harvesting these lymph nodes. ${ }^{25,27}$

Several studies have reported good outcomes from use of the groin VLN flap for treatment of lymphedema. In their study of the groin VLN flap, Cheng et al reported a significantly greater decrease in limb circumference in patients undergoing groin VLNT versus those receiving physical therapy (40.4\% versus $8.3 \%$, respectively). ${ }^{28} \mathrm{~A}$ recent review published by Scaglioni et al found that $70.4 \%$ of the 138 patients undergoing groin VLNT reported that the procedure benefited their lymphedema treatment. ${ }^{20}$ In a study of 17 groin VLN flaps, Becker et al found that the upper limb volumetric perometry measurements returned to normal in $42 \%$ of patients with postmastectomy lymphedema and decreased in $50 \%$ of patients. ${ }^{29}$ Lin et al, meanwhile, found decreased arm circumference in 12 out of 13 patients utilizing the groin VLN flap for the treatment of upper extremity lymphedema. ${ }^{30}$

\section{Supraclavicular Flap}

A flap based on the supraclavicular branch of the transverse cervical artery was first described by Kazanjian and Converse in $1949 .^{31,32}$ The flap was used sparingly until the 1990s, when cadaveric studies by Pallua et al resulted in refinement of the flap that increased its reliability and led to its recent resurgence for head and neck reconstruction, and more recently, for $\mathrm{VLNT}^{33,34}$ (-Fig. 2). The lymph nodes of the supraclavicular VLN flap belong to the cervical $\mathrm{Vb}$ lymph node level and are centered around the perforator of the transverse cervical vessels and branches of the external jugular vein. While these lymph nodes drain vital structures including the lung, esophagus, and thyroid, their removal is generally inconsequential, as evidenced by their routine harvest in oncological lymph node dissections. ${ }^{35}$
One benefit of using the supraclavicular flap is the wellhidden scar at the recipient site that can be easily concealed within the patient's clothing. Additionally, harvest of the supraclavicular lymph nodes does not increase the risk of iatrogenic lymphedema as greatly as in the groin-based or axillary-based flaps, although one case of secondary lymphedema has been reported in the literature. ${ }^{36,37}$ In addition, the flap dimensions and size are considerably smaller than other sites given the thin tissue usually present in this region, although studies have also shown that the number of usable lymph nodes for inclusion within the flap are lower than other available donor sites. ${ }^{35,38}$

Despite the wide applicability of the supraclavicular flap, safe harvesting requires full knowledge of the local anatomy and understanding of potential donor site complications. For example, there is significant anatomic variability of the arterial and venous supplies of the supraclavicular region. ${ }^{36}$ Surgeons performing this procedure must be aware of the variations in the anatomy of the transverse cervical artery: in anatomical studies, the TCA most often takes its origin from the thyrocervical trunk $(80 \%)$ or directly from the subclavian artery (20\%). There are also reports that the TCA may arise as a branch of the internal mammary artery. ${ }^{39}$ The surgeon must be able to adjust the approach accordingly to ensure blood supplies to the lymph nodes are preserved during the dissection. Additionally, there are many vital structures in the supraclavicular region including the carotid artery, internal jugular vein, thoracic duct, and phrenic nerve. Careful surgical technique is necessary to avoid damaging any of these structures. ${ }^{40}$

Outcomes of supraclavicular VLN flaps are limited in the literature, but those that have been described have been positive. A study comparing supraclavicular VLNT with lymphovenous anastomosis (LVA) for advanced stage lower extremity lymphedema found that the supraclavicular VLNT was more effective than LVA at improving lymphatic function. ${ }^{41}$ In a prospective study of 100 consecutive cases of the supraclavicular VLNT reporting donor site outcomes, only 2 donor site infections, no cases of secondary lymphedema, the presence of well-healing scars, and satisfaction with the aesthetic result of the donor site by most patients. ${ }^{36}$ While initial results of the supraclavicular VLN flap for the treatment of lymphedema are encouraging, additional

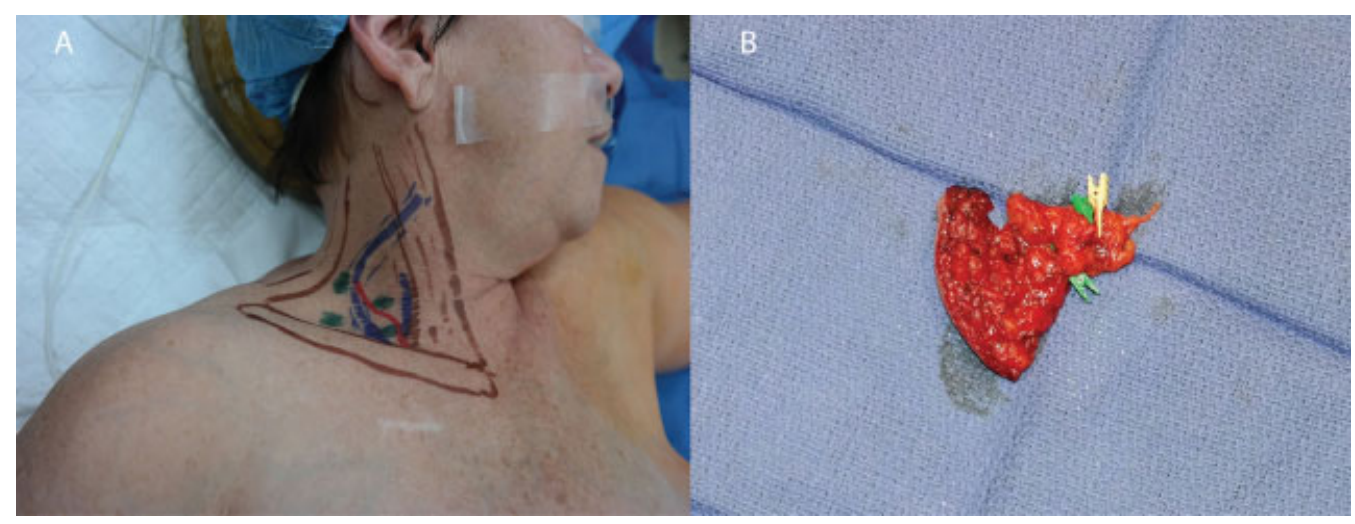

Fig. 2 Supraclavicular vascularized lymph node flap. (A) Skin markings for the supraclavicular flap; (B) supraclavicular flap after harvest. 
studies investigating the outcomes of this procedure are still needed.

\section{Submental Flap}

The submental flap was initially described in 1990 as a reliable flap for head and neck reconstruction. ${ }^{42}$ Since its introduction into clinical use, further cadaveric and clinical studies have found the submental flap to be versatile as both a free or pedicled flap, and refinement has allowed versatility in its design. ${ }^{43}$ As a result of this, the flap was recently adapted for use in VLNT by Cheng et al. ${ }^{44}$ The submental flap is nourished by the submental artery, which is a branch of the facial artery. From a cadaveric study, an average of $3.3 \pm 1.5$ lymph nodes can be identified within the flap. ${ }^{44}$

The submental VLN flap offers several advantages over other flaps. First, the submental region is a remote VLN source that eliminates the chance of inducing iatrogenic upper or lower extremity lymphedema. ${ }^{44}$ Therefore, the flap is particularly useful for the treatment of lower extremity lymphedema where harvest of the groin donor site is typically avoided. Moreover, the flap is unlikely to cause iatrogenic lymphedema in the head and neck. For surgeons comfortable with head and neck anatomy, the submental VLNT has consistent and reliable anatomy, although some minor variations of this flap do occur near key structures within the upper neck. ${ }^{45}$

The main concern with the use of the submental VLN flap is the possibility of injuring the marginal mandibular nerve, which runs superficial to the facial vessels. Injury to this nerve can lead to asymmetries in facial movement, which are noticeable on opening the mouth, smiling, or grimacing. ${ }^{46,47}$ In fact, Cheng et al report finding subtle asymmetries in $\sim 10 \%$ of patients in the early postoperative period following use of the submental VLN flap, although all cases resolve on their own without permanent nerve injury. ${ }^{45}$ Furthermore, the pedicle length is short, which may require the inclusion of the facial vessels. ${ }^{44}$ Finally, the donor site scar is located on the mandible, which makes it difficult to conceal, although Cheng et al reported that in patients receiving submental VLNT, there was no complaint of donor site scar appearance or location in any patient. ${ }^{44}$

Several studies in the literature have validated the use of submental VLN flap for the treatment of upper and lower extremity lymphedema. One study by Patel et al found a mean reduction rate in limb circumference of $41.4 \%$ in patients with upper and lower extremity lymphedema at a mean follow-up of 18.3 months. ${ }^{6}$ Another study by Patel et al investigating 10 patients undergoing submental VLN flap for lower extremity lymphedema found a $35.2 \%$ reduction in limb circumference at a mean follow-up of 16.1 months. Evaluation using the Health-Related Quality of Life (HRQoL) survey revealed significant changes occurring as early as 3 months following surgery, while at 12 -month postoperatively, the authors found significant improvements in all domains of the HRQoL in patients receiving the submental flap. ${ }^{48}$ Similarly, Cheng et al reported significant increases in the condition-specific quality of life assessment tool for lymphedema of the limbs (LYMQOL) scores of all seven patients included in their study and reported significant reduction in limb circumference compared with baseline. ${ }^{44}$ Finally, a comprehensive review performed by Scaglioni et al found that among various different donor-sites for VLNT, the submental nodes were the most effective, with $100 \%$ of patients $(n=8)$ reporting that they benefited from this method of lymphedema treatment. ${ }^{20}$

\section{Lateral Thoracic Lymph Node Flap}

The lateral thoracic lymph node flap involves the transfer of lymph nodes from the lower part of the axilla between the anterior and posterior axillary lines. Anatomical studies of the lymphatic drainage of the axilla have demonstrated discrete organization of the sentinel lymph node drainage of the thorax and upper extremity, and this forms the basis of lymph node transfer from this region. ${ }^{49,50}$ The dominant vascular supply to these nodes is via the lateral thoracic artery and vein, ${ }^{51}$ and the reliability of the lateral thoracic pedicle for free and pedicled flaps is well established. ${ }^{52,53}$ The artery is absent in around $12.5 \%$ of sides, in which case the thoracodorsal artery provides the vascular supply to those lymph nodes. ${ }^{51}$ An anatomical study revealed on average $13.40 \pm 3.13$ lymph nodes within the flap. Perforators to the overlying skin were present in $87.5 \%$ of anatomical dissections, allowing for transfer of a skin paddle. ${ }^{54}$

The flap is harvested via an incision at the anterior axillary line, and dissection is performed in the suprafascial plane as far cephalad as the lateral border of the pectoralis minor and the second intercostal brachial nerve. Dissection of the pedicle is continued until sufficient arterial diameter is achieved; arterial caliber is on average $1.3 \mathrm{~mm}$ and venous caliber $2.6 \mathrm{~mm}^{51}$

The main advantage of the flap is an inconspicuous scar, relatively consistent anatomy, and longer pedicle length than with other peripheral lymph node flaps. There is also the potential for dividing the flap on the different vascular pedicles for multilevel transfer.

The main disadvantage is the potential to cause upper extremity donor site lymphedema. For this reason, it is imperative to use reverse lymphatic mapping to avoid the lymphatic drainage to the upper extremity; ${ }^{26}$ this is typically localized cephalad to the second intercostal brachial nerve and lateral to the lateral thoracic vein. ${ }^{55}$

Limited published clinical evidence is available. Barreiro et al reported outcomes of a series of seven patients, with good outcomes and functioning lymph nodes demonstrated on lymphoscintigraphy. ${ }^{51}$ Further clinical reports are necessary to further establish the efficacy and safety of the lateral thoracic lymph node flap.

\section{Gastroepiploic Flap}

The use of the greater omentum as a pedicle or free flap has been reported in the management of patients with lymphedema as early as $1967 .{ }^{56}$ Although omental flaps were traditionally harvested with an open laparotomy procedure, a 
laparoscopic approach is now more commonly used to minimize donor-site morbidity. ${ }^{57}$ The gastroepiploic flap is a modification of the free omental flap, such that the omental tissue is harvested laparoscopically and is limited to the area adjacent to the gastroepiploic vascular arcade, since the lymph nodes are located around these vessels ${ }^{58}(-$ Fig. 3). This allows for the creation of relatively small lymph node flap (mean: $3 \mathrm{~cm} \times 7 \mathrm{~cm}$ ) that allows placement in the distal extremity with minimal impact on cosmetics. ${ }^{57}$ The flap is harvested using the right gastroepiploic artery due to greater accessibility compared with the left side. Moreover, it has been well described in the literature that ligation and use of the right gastroepiploic artery does not increase the risk of gastric ischemia or other abdominal complications. . $^{57,59,60}$

The main benefit of the gastroepiploic flap is the ability to avoid iatrogenic lymphedema of the extremities. To date, there is no report in the literature showing iatrogenic intraabdominal lymphedema following gastroepiploic flap harvest. ${ }^{58}$ Furthermore, the scars are minimal and identical to those produced from other laparoscopic procedures and are hidden under the patient's clothing. Additionally, the versatility in the size of the flap allows for use in various donor sites.

As the gastroepiploic flap is harvested from the intraperitoneal space, there is a risk of causing abdominal complications similar to other laparoscopic procedures. Although rare, there are reports in the literature of significant gastrointestinal complications that include incisional hernia, peritonitis, injury to intra-abdominal organs, and bowel obstruction, among others. ${ }^{61,62}$ Compared with the traditional open approach to omental flap harvest, the laparoscopic approach significantly reduces these donor-site complications. $^{63}$ Furthermore, the use of laparoscopy for the harvest of the gastroepiploic flap means postoperative pain is decreased, ambulation can be resumed sooner, and operative times are decreased. ${ }^{58,62}$

Reported outcomes from the use of the gastroepiploic flaps in the literature have been promising. A study by Ciudad et al found a statistically significant improvement in scores on the LYMQOL questionnaire following use of the gastroepiploic flap. Furthermore, all patients reported satisfaction with the cosmetic result, significant improvement in symptoms, and had significant reduction rates of the affected limb circumference. ${ }^{57}$ An additional study looking at the use of double gastroepiploic flaps in six patients with lymphedema found that the circumference of the lymphedematous limb

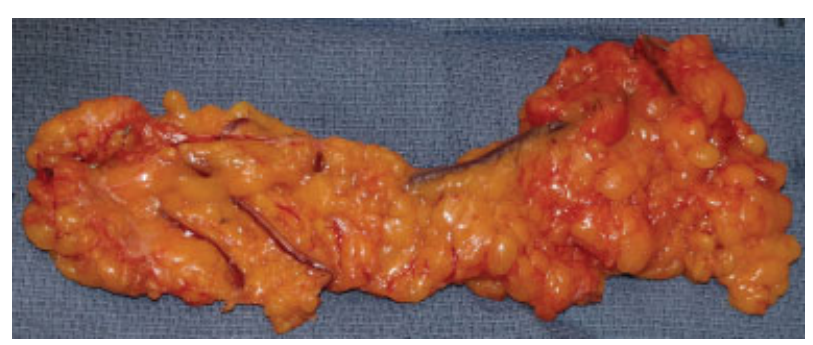

Fig. 3 Gastroepiploic vascularized lymph node flap after harvest. was reduced by $43.7 \%$ at a mean follow-up of 10 months. ${ }^{64}$ Finally, according to one review looking at benefits to patients from vascularized lymph node transfer, $60 \%$ of omental flaps based on the gastroepiploic vessels resulted in subjective benefit to patients in their treatment of lymphedema. ${ }^{20}$ Innovations in the harvest of gastroepiploic flap harvest, including the use of robotic surgery, will likely continue to improve the outcomes and reduce complications of this procedure in the future. ${ }^{65}$

\section{Jejunal Mesenteric Lymph Node Flap}

The jejunal mesenteric lymph node flap is also an option for patients that wish to avoid any risk of donor site extremity lymphedema following vascularized lymph node transfer. The traditional pedicled enteromesenteric bridge procedure introduced by Kinmonth et al in 1978 for the treatment of lymphedema has been revisited using microsurgery to overcome many of its limitations. These include the potential for herniation and the need to perform resection of a portion of ileum, which although contained fewer lymphatics than the jejunum, was selected to provide adequate reach, and preliminary studies have confirmed its efficacy. ${ }^{66,67}$

The flap has been described both as a flap harvested from the periphery of the mesentery to incorporate a vascular arcade adjacent to the jejunum, potentially risking ischemic bowel complications, as well as a flap harvested from closer to the root of the mesentery, that avoids disruption to the vascular supply to the adjacent bowel segment. ${ }^{68-70}$ The flap is harvested either through a short upper midline incision or an abdominoplasty incision (following previous or simultaneous abdominally based breast reconstruction), although laparoscopic or robotic harvest is feasible. The longest loop of the third part of the jejunum is identified, and a flap based on either the second, third, or fourth mesenteric branch is designed where a concentration of lymph nodes can be palpated. This proximal segment has significantly more lymph nodes than the other segments. ${ }^{70}$ To avoid a risk of internal hernia, only the anterior peritoneum is incised to incorporate all mesenteric tissue with multiple lymph nodes within the adjacent branches of the superior mesenteric vessels, with the posterior peritoneum left intact. The advantages of the flap include consistent vascular anatomy, a reliable lymph node packet, no risk of donor site lymphedema, avoidance of radioisotope use, and a well-concealed scar. Disadvantages include the need for intraabdominal procedure; the attendant risks of injury to viscera, adhesions, and internal hernia; and the need for bowel resection in the case of bowel ischemia (-Fig. 4).

Preliminary results of this flap have been encouraging. Coriddi et al reported outcomes in 15 patients for treatment of upper $(n=8)$ or lower $(n=7)$ extremity lymphedema. There was one total flap loss; 12 patients had subjective improvement (87.5\%), and $7 / 10$ patients with preoperative measurements had objective improvement in their lymphedema. ${ }^{70}$ 


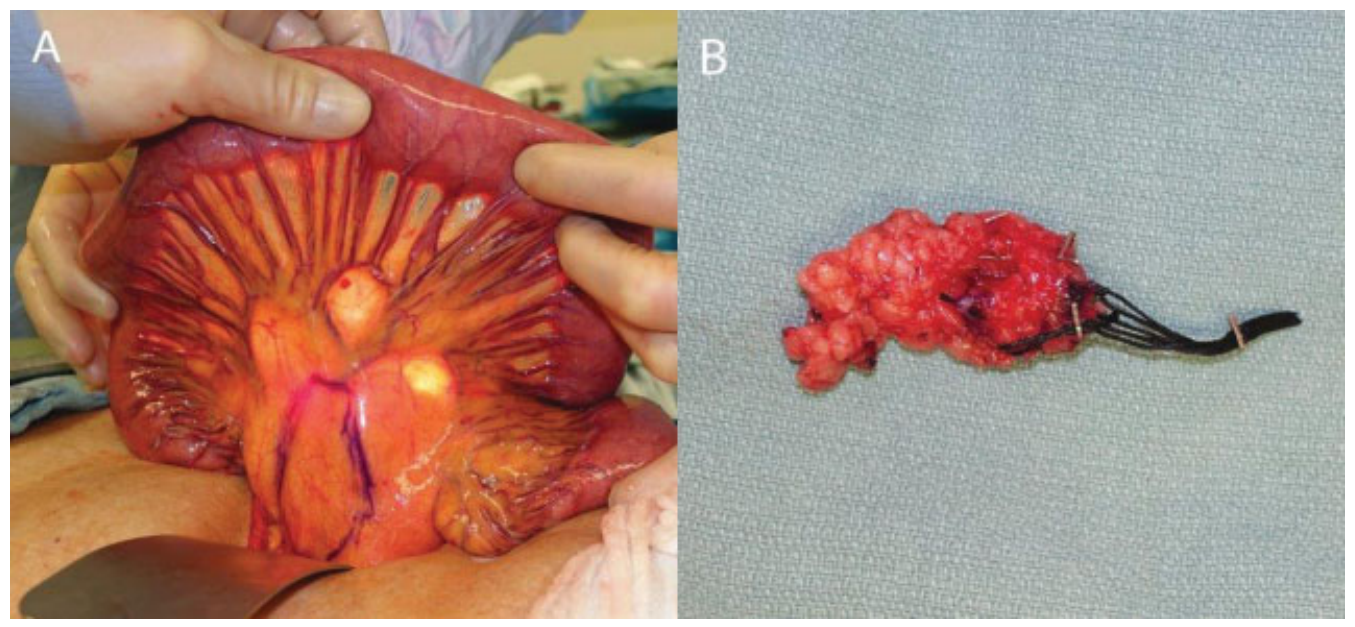

Fig. 4 Jejunal mesenteric vascularized lymph node flap. (A) Flap markings on peritoneum; (B) mesenteric flap after harvest.

\section{Conclusion}

Vascularized lymph node transfer is an effective technique for the physiological treatment of established lymphedema, and several techniques have been described. The choice of technique is dependent on patient acceptable of scar location, risk of donor site lymphedema, and acceptance of the risks of an intra-abdominal procedure. The choice of orthotopic or heterotopic placement of the lymph node transplant is dependent on acceptance of scar locations, where the pitting edema is localized, and outcomes from dual level lymph node transfers are awaited. ${ }^{64}$ Reverse lymphatic mapping is essential for lymph nodes harvested from within the axillary or inguinal lymph node basins to avoid the dreaded consequence of donor site lymphedema, and surgeons performing these procedures must have a detailed knowledge of anatomy of these regions to avoid straying into the lymphatic drainage pathways of the extremities. Further outcomes data for more recently described flaps is awaited to aid surgical treatment algorithms for patients with lymphedema. ${ }^{54,70,71}$

\section{Conflict of Interest}

None.

\section{References}

1 Chang DW, Masia J, Garza R III, Skoracki R, Neligan PC. Lymphedema: Surgical and Medical Therapy. Plast Reconstr Surg 2016; 138(3, Suppl):209S-218S

2 Gratzon A, Schultz J, Secrest K, Lee K, Feiner J, Klein RD. Clinical and psychosocial outcomes of vascularized lymph node transfer for the treatment of upper extremity lymphedema after breast cancer therapy. Ann Surg Oncol 2017;24(06): 1475-1481

3 Dionyssiou D, Demiri E, Tsimponis A, et al. A randomized control study of treating secondary stage II breast cancer-related lymphoedema with free lymph node transfer. Breast Cancer Res Treat 2016;156(01):73-79

4 Shesol BF, Nakashima R, Alavi A, Hamilton RW. Successful lymph node transplantation in rats, with restoration of lymphatic function. Plast Reconstr Surg 1979;63(06):817-823
5 Chen HC, O'Brien BM, Rogers IW, Pribaz JJ, Eaton CJ. Lymph node transfer for the treatment of obstructive lymphoedema in the canine model. Br J Plast Surg 1990;43(05):578-586

6 Patel KM, Lin CY, Cheng MH. From theory to evidence: long-term evaluation of the mechanism of action and flap integration of distal vascularized lymph node transfers. J Reconstr Microsurg 2015;31(01):26-30

7 Suami H, Scaglioni MF, Dixon KA, Tailor RC. Interaction between vascularized lymph node transfer and recipient lymphatics after lymph node dissection-a pilot study in a canine model. J Surg Res 2016;204(02):418-427

8 Ito R, Zelken J, Yang CY, Lin CY, Cheng MH. Proposed pathway and mechanism of vascularized lymph node flaps. Gynecol Oncol 2016;141(01):182-188

9 Cheng MH, Huang JJ, Wu CW, et al. The mechanism of vascularized lymph node transfer for lymphedema: natural lymphaticovenous drainage. Plast Reconstr Surg 2014;133(02):192e-198e

10 Yan A, Avraham T, Zampell JC, Aschen SZ, Mehrara BJ. Mechanisms of lymphatic regeneration after tissue transfer. PLoS One 2011;6 (02):e17201

11 Aschen SZ, Farias-Eisner G, Cuzzone DA, et al. Lymph node transplantation results in spontaneous lymphatic reconnection and restoration of lymphatic flow. Plast Reconstr Surg 2014;133 (02):301-310

12 Viitanen TP, Visuri MT, Hartiala P, et al. Lymphatic vessel function and lymphatic growth factor secretion after microvascular lymph node transfer in lymphedema patients. Plast Reconstr Surg Glob Open 2013;1(02):1-9

13 Hara H, Mihara M, Seki Y, Todokoro T, Iida T, Koshima I. Comparison of indocyanine green lymphographic findings with the conditions of collecting lymphatic vessels of limbs in patients with lymphedema. Plast Reconstr Surg 2013;132(06):1612-1618

14 Huang JJ, Gardenier JC, Hespe GE, et al. Lymph node transplantation decreases swelling and restores immune responses in a transgenic model of lymphedema. PLoS One 2016;11(12): e0168259

15 Granzow JW, Soderberg JM, Dauphine C. A novel two-stage surgical approach to treat chronic lymphedema. Breast J 2014; 20(04):420-422

16 Nicoli F, Constantinides J, Ciudad P, et al. Free lymph node flap transfer and laser-assisted liposuction: a combined technique for the treatment of moderate upper limb lymphedema. Lasers Med Sci 2015;30(04):1377-1385

17 Campisi CC, Ryan M, Boccardo F, Campisi C. Fibro-lipo-lymphaspiration with a lymph vessel sparing procedure to treat 
advanced lymphedema after multiple lymphatic-venous anastomoses: the complete treatment protocol. Ann Plast Surg 2017;78 (02):184-190

18 Clodius L, Smith PJ, Bruna J, Serafin D. The lymphatics of the groin flap. Ann Plast Surg 1982;9(06):447-458

19 Tobbia D, Semple J, Baker A, Dumont D, Johnston M. Experimental assessment of autologous lymph node transplantation as treatment of postsurgical lymphedema. Plast Reconstr Surg 2009;124 (03):777-786

20 Scaglioni MF, Arvanitakis M, Chen Y-C, Giovanoli P, Chia-Shen Yang J, Chang EI. Comprehensive review of vascularized lymph node transfers for lymphedema: outcomes and complications. Microsurgery 2016

21 Scaglioni MF, Suami H. Lymphatic anatomy of the inguinal region in aid of vascularized lymph node flap harvesting.J Plast Reconstr Aesthet Surg 2015;68(03):419-427

22 Becker C. Microsurgical procedures: vascularized lymph node transfer from the groin. Principles and Practice of Lymphedema Surgery. Philadelphia, PA: Elsevier; 2016:122-132

23 Patel KM, Chu SY, Huang JJ, Wu CW, Lin CY, Cheng MH. Preplanning vascularized lymph node transfer with duplex ultrasonography: an evaluation of 3 donor sites. Plast Reconstr Surg Glob Open 2014;2(08):e193

24 Dayan JH, Dayan E, Kagen A, et al. The use of magnetic resonance angiography in vascularized groin lymph node transfer: an anatomic study. J Reconstr Microsurg 2014;30(01):41-45

25 Raju A, Chang DW. Vascularized lymph node transfer for treatment of lymphedema: a comprehensive literature review. Ann Surg 2015;261(05):1013-1023

26 Vignes S, Blanchard M, Yannoutsos A, Arrault M. Complications of autologous lymph-node transplantation for limb lymphoedema. Eur J Vasc Endovasc Surg 2013;45(05):516-520

27 Dayan JH, Dayan E, Smith ML. Reverse lymphatic mapping: a new technique for maximizing safety in vascularized lymph node transfer. Plast Reconstr Surg 2015;135(01):277-285

28 Cheng MH, Chen SC, Henry SL, Tan BK, Lin MC, Huang JJ. Vascularized groin lymph node flap transfer for postmastectomy upper limb lymphedema: flap anatomy, recipient sites, and outcomes. Plast Reconstr Surg 2013;131(06):1286-1298

29 Becker C, Assouad J, Riquet M, Hidden G. Postmastectomy lymphedema: long-term results following microsurgical lymph node transplantation. Ann Surg 2006;243(03):313-315

30 Lin $\mathrm{CH}$, Ali R, Chen SC, et al. Vascularized groin lymph node transfer using the wrist as a recipient site for management of postmastectomy upper extremity lymphedema. Plast Reconstr Surg 2009;123(04):1265-1275

31 Telang P, Jagannathan M, Devale M. A study of the use of the supraclavicular artery flap for resurfacing of head, neck, and upper torso defects. Indian J Plast Surg 2009;42(01):4-12

32 Kazanjian VH, Converse JM. Surgical Treatment of Facial Injuries. 3rd ed. BaltimoreWilliams \& Wilkins; 1974

33 Pallua N, Machens HG, Rennekampff O, Becker M, Berger A. The fasciocutaneous supraclavicular artery island flap for releasing postburn mentosternal contractures. Plast Reconstr Surg 1997;99 (07):1878-1884, discussion 1885-1886

34 Pallua N, Magnus Noah E. The tunneled supraclavicular island flap: an optimized technique for head and neck reconstruction. Plast Reconstr Surg 2000;105(03):842-851, discussion 852-854

35 Bank J, Chang DW. Microsurgical procedures: vascularized lymph node transfer from the supraclavicular region. Principles and Practice of Lymphedema Surgery. Philadelphia, PA: Elsevier; 2016:148-154

36 Mardonado AA, Chen R, Chang DW. The use of supraclavicular free flap with vascularized lymph node transfer for treatment of lymphedema: A prospective study of 100 consecutive cases. J Surg Oncol 2017;115(01):68-71

37 Lee M, McClure E, Reinertsen E, Granzow JW. Lymphedema of the upper extremity following supraclavicular lymph node harvest. Plast Reconstr Surg 2015;135(06):1079e-1082e
38 Huang JJ. Lymph node transfer to distal extremity. Lymphedema. Cham: Springer; 2015:279-288

39 Sapountzis S, Singhal D, Rashid A, Ciudad P, Meo D, Chen HC. Lymph node flap based on the right transverse cervical artery as a donor site for lymph node transfer. Ann Plast Surg 2014;73(04): 398-401

40 Ooi ASH, Chang DW. 5-step harvest of supraclavicular lymph nodes as vascularized free tissue transfer for treatment of lymphedema. J Surg Oncol 2017;115(01):63-67

41 Akita S, Mitsukawa N, Kuriyama M, et al. Comparison of vascularized supraclavicular lymph node transfer and lymphaticovenular anastomosis for advanced stage lower extremity lymphedema. Ann Plast Surg 2015;74(05):573-579

42 Martin D, Pascal JF, Baudet J, et al. The submental island flap: a new donor site. Anatomy and clinical applications as a free or pedicled flap. Plast Reconstr Surg 1993;92(05):867-873

43 Shi CL, Wang XC. Reconstruction of lower face defect or deformity with submental artery perforator flaps. Ann Plast Surg 2012;69 (01):41-44

44 Cheng MH, Huang JJ, Nguyen DH, et al. A novel approach to the treatment of lower extremity lymphedema by transferring a vascularized submental lymph node flap to the ankle. Gynecol Oncol 2012;126(01):93-98

45 Cheng MH, Patel KM. Microsurgical procedures: vascularized lymph node transfer from the submental region. Principles and Practice of Lymphedema Surgery. Philadelphia, PA: Elsevier; 2016:138-147

46 Steinbacher J, Tinhofer IE, Meng S, et al. The surgical anatomy of the supraclavicular lymph node flap: a basis for the free vascularized lymph node transfer. J Surg Oncol 2017;115(01):60-62

47 Batra APS, Mahajan A, Gupta K. Marginal mandibular branch of the facial nerve: an anatomical study. Indian J Plast Surg 2010;43 (01):60-64

48 Patel KM, Lin CY, Cheng MH. A prospective evaluation of lymphedema-specific quality-of-life outcomes following vascularized lymph node transfer. Ann Surg Oncol 2015;22(07): 2424-2430

49 Suami H, O'Neill JK, Pan WR, Taylor GI. Superficial lymphatic system of the upper torso: preliminary radiographic results in human cadavers. Plast Reconstr Surg 2008;121(04):1231-1239

50 Smith ML, Molina BJ, Dayan E, et al. Heterotopic vascularized lymph node transfer to the medial calf without a skin paddle for restoration of lymphatic function: proof of concept. J Surg Oncol 2017;115(01):90-95

51 Barreiro GC, Baptista RR, Kasai KE, et al. Lymph fasciocutaneous lateral thoracic artery flap: anatomical study and clinical use. J Reconstr Microsurg 2014;30(06):389-396

52 Bhattacharya S, Bhagia SP, Bhatnagar SP, Aabdi SM, Chandra R. The anatomical basis of the lateral thoracic flap. Eur J Plast Surg 1990; 13:238-240

53 Harii K, Torii S, Sekiguchi J. The free lateral thoracic flap. Plast Reconstr Surg 1978;62(02):212-222

54 Tinhofer IE, Meng S, Steinbacher J, et al. The surgical anatomy of the vascularized lateral thoracic artery lymph node flap-A cadaver study. J Surg Oncol 2017

55 Clough KB, Nasr R, Nos C, Vieira M, Inguenault C, Poulet B. New anatomical classification of the axilla with implications for sentinel node biopsy. Br J Surg 2010;97(11):1659-1665

56 Goldsmith HS, De los Santos R. Omental transposition in primary lymphedema. Surg Gynecol Obstet 1967;125(03):607-610

57 Ciudad P, Maruccia M, Socas J, et al. The laparoscopic right gastroepiploic lymph node flap transfer for upper and lower limb lymphedema: technique and outcomes. Microsurgery 2017;37(03):197-205

58 Agko M, Ciudad P, Chen HC. Histo-anatomical basis of the gastroepiploic vascularized lymph node flap: the overlooked "micro" lymph nodes. J Plast Reconstr Aesthet Surg 2018;71(01):118-120

59 Suma H. Gastroepiploic artery graft in coronary artery bypass grafting. Ann Cardiothorac Surg 2013;2(04):493-498 
60 Suma H, Tanabe H, Takahashi A, et al. Twenty years experience with the gastroepiploic artery graft for CABG. Circulation 2007; 116(11, Suppl)I188-I191

61 Saltz R, Stowers R, Smith M, Gadacz TR. Laparoscopically harvested omental free flap to cover a large soft tissue defect. Ann Surg 1993;217(05):542-546, discussion 546-547

62 Zaha H, Inamine S. Laparoscopically harvested omental flap: results for 96 patients. Surg Endosc 2010;24(01):103-107

63 van Garderen JA, Wiggers T, van Geel AN. Complications of the pedicled omentoplasty. Neth J Surg 1991;43(05):171-174

64 Ciudad P, Manrique OJ, Date S, et al. Double gastroepiploic vascularized lymph node tranfers to middle and distal limb for the treatment of lymphedema. Microsurgery 2017;37(07):771-779

65 Ciudad P, Date S, Lee MH, et al. Robotic harvest of a right gastroepiploic lymph node flap. Arch Plast Surg 2016;43(02):210-212

66 Kinmonth JB, Hurst PA, Edwards JM, Rutt DL. Relief of lymph obstruction by use of a bridge of mesentery and ileum. Br J Surg 1978;65(12):829-833
67 Hurst PA, Stewart G, Kinmonth JB, Browse NL. Long term results of the enteromesenteric bridge operation in the treatment of primary lymphoedema. Br J Surg 1985;72(04):272-274

68 Coriddi M, Skoracki R, Eiferman D. Vascularized jejunal mesenteric lymph node transfer for treatment of extremity lymphedema. Microsurgery 2017;37(02):177-178

69 Schaverien MV, Hofstetter WL, Selber JC. Vascularized jejunal mesenteric lymph node transfer for lymphedema: a novel approach. Plast Reconstr Surg 2017

70 Coriddi M, Wee C, Meyerson J, Eiferman D, Skoracki R. Vascularized jejunal mesenteric lymph node transfer: a novel surgical treatment for extremity lymphedema. J Am Coll Surg 2017;225 (05):650-657

71 Ciudad P, Agko M, Perez Coca JJ, et al. Comparison of long-term clinical outcomes among different vascularized lymph node transfers: 6-year experience of a single center's approach to the treatment of lymphedema. J Surg Oncol 2017;116(06): $671-682$ 